\title{
Estudo de Casos: Um Recurso Didático para o Ensino de Química no Nível Médio
}

Fabiele Cristiane Dias Broietti

Flaveli Aparecida de Souza Almeida

Renata Cristina Mello Alves Silva

\begin{abstract}
Resumo
O presente trabalho teve como objetivo abordar os rótulos de produtos alimentícios possibilitando aos alunos do ensino médio a compreensão de termos como diet, light, normal, caloria, \%VD e sódio por meio da aplicação da metodologia do estudo de casos. O estudo foi realizado em uma turma de 20 ano do Ensino Médio de uma escola pública do estado do Paraná. O caso tratava de uma conversa entre a avó e sua neta sobre as dúvidas para se alimentar melhor com a interpretação das informações contidas nos rótulos. O trabalho consistiu na aplicação de um questionário no início e no final das atividades, leitura do caso, análise de alguns rótulos, leitura de artigos, discussão da problemática e apresentação oral da resolução do caso pelos alunos. Os resultados com a aplicação do caso sugerem que se trata de uma estratégia eficiente que pode ser empregada pelo professor numa concepção de ensino que prioriza a aprendizagem.
\end{abstract}

Palavras-chave: estudo de casos, ensino médio, rótulos de alimentos.

\section{Abstract}

\section{Cases Study: A Resource for high school chemistry teaching}

The present study aimed to address alimentary products labels enabling high school students to understand terms such as diet, light, normal, calories, VD\% and sodium applying the case study methodology. The study was conducted in a 2nd year of high school class at a public school in Paraná state. The case was a conversation between a grandmother and her granddaughter about how to eat better interpreting the information on the labels. The work consisted of a questionnaire at the beginning and the end of activities, reading the case, analysis of some labels, reading articles, discussion of the problem and an oral presentation of a resolution to the case by the students. The results presented by the application of the case suggest that is an effective strategy that can be used by a teacher in a teaching concept that emphasizes learning.

Keywords: cases study, high school, food labels. 


\section{Introdução}

O método do estudo de casos é uma variante do método Aprendizagem Baseada em Problemas também conhecido como "Problem Based Learning (PBL)" que oferece aos estudantes a oportunidade de direcionar sua própria aprendizagem em situações relativamente complexas (Waterman, 1998).

No método do estudo de casos, o ato de contar histórias, em que indivíduos enfrentam decisões ou dilemas, reais ou fictícios, faz com que o aluno se familiarize com os personagens e circunstâncias mencionadas no caso, de modo a compreender a situação e o contexto nele presente, com o intuito de solucionar o fato apresentado.

Neste contexto, o papel principal do professor consiste em ser um articulador na busca do conhecimento e ajudar o estudante a trabalhar com o tema proposto, desde a análise do problema considerado até as possíveis soluções envolvidas naquela situação.

A aplicação do método de estudo de casos pode ser diversificada e depende da forma como o professor espera que os alunos trabalhem na solução do problema proposto. Herreid (1998a) elaborou um esquema de classificação e sugeriu que os casos podiam ser explorados, pelo professor, nos seguintes formatos:

- de tarefa individual: o caso tem o caráter de uma tarefa que o aluno deve solucionar e que implica na elaboração posterior de uma explicação histórica dos eventos que conduziram à sua resolução;

- de aula expositiva: o caso tem a característica de uma história contada pelo professor aos seus alunos, de maneira muito elaborada e com objetivos específicos;

- de discussão: o caso é apresentado pelo professor como um dilema. Os alunos são questionados a respeito das suas perspectivas e sugestões com relação à resolução do mesmo;

- de atividades em pequenos grupos: os casos são histórias que devem ser solucionadas e dizem respeito ao contexto social e/ou profissional em que os alunos estão imersos. Uma característica essencial é que os casos são analisados por grupos pequenos de estudantes, que trabalham em colaboração. O professor, neste contexto, desempenha um papel de facilitador durante as discussões, em vez de um papel didático e diretivo.

No ensino de química, há lugar para qualquer uma dessas formas de abordar o estudo de casos, dependendo exclusivamente de como o professor busca trabalhar com seus alunos e da maneira que deseja conduzir os alunos ao conhecimento proposto.

Outro fator importante para o ensino e aprendizagem, considerado por Herreid (1998b), é que o caso pode seguir alguns aspectos importantes na sua elaboração, tais como: deve ter utilidade pedagógica; ser relevante ao leitor; despertar interesse pela questão; deve ser atual; 
curto; provocar um conflito; criar empatia com os personagens; forçar uma decisão; ter aplicabilidade geral; narrar uma história e incluir citações.

Após a escolha da forma como o caso será trabalhado com os alunos e a elaboração do mesmo, outra importante etapa consiste na formulação de questões a serem trabalhadas pelos alunos, considerando os objetivos esperados com a sua aplicação. Nessa etapa devem ser contemplados os conteúdos científicos, as habilidades que se deseja que os alunos adquiram, as formas como os conceitos a serem aprendidos serão desenvolvidos e sua execução na formulação da possível solução a ser apresentada.

Como essa etapa envolve a tomada de decisão, existem vários modelos que podem auxiliar o professor na elaboração de questões, como os citados e discutidos no livro Estudo de casos no Ensino de Química (Sá e Queiroz, 2009).

\section{Estudo de Casos no Ensino de Química}

No Brasil, a metodologia de ensino pautada em estudo de casos ainda se apresenta de forma tímida, no qual o acesso a casos prontos é pouco encontrado. Realizando um levantamento sobre a utilização deste método encontramos poucos trabalhos como o realizado por Brito e Sá (2010), que relatam o estudo de casos como estratégia para estimular a argumentação de alunos do ensino médio a respeito de questões sócio-científicas relacionadas ao tema biocombustíveis. Outro recente trabalho encontrado foi o de Pinheiro e outros (2010). Os autores descrevem que o método de estudo de casos, apesar de não ser muito utilizado no ensino superior, especificamente nos cursos de Química, vem se configurando como eficiente no que se refere à aprendizagem e para uma formação mais ampla do aluno. Eles relatam suas experiências com a aplicação do método com licenciandos e estes, aplicam a metodologia no ensino médio, utilizando como tema o biodiesel. Como resultado deste trabalho os autores conseguiram aliar a experimentação, a leitura, à aproximação entre conhecimento científico-tecnológico e a formação do futuro professor com novas metodologias que privilegiam aspectos tecnológicos, sociais, econômicos e ambientais da Química.

Outra contribuição tem sido feita, por exemplo, pelo site do grupo de pesquisa em Ensino de Química do Instituto de Química de São $\operatorname{Carlos}^{1}$ que disponibiliza exemplos de casos e sugestões de atividades. Mais contribuições sobre a aplicação desta metodologia podem ser encontradas por meio de trabalhos divulgados em congressos e eventos da área que relatam propostas didáticas para o ensino de ciências e, principalmente, pelo trabalho de aplicação e compilação realizado no livro Estudo de Casos no Ensino de Química (Sá e Queiroz, 2009), que

\footnotetext{
${ }^{1}$ Disponível em: http://www.gpeqsc.com.br, acessada em dezembro de 2010.
} 
apresenta o uso do método aplicado nos cursos de ensino superior e que serve de referência para a construção e utilização do método no ensino médio.

Com o método de estudo de casos, corretamente aplicado, o processo transforma-se em uma poderosa ferramenta no processo de ensino e aprendizado, e assim, portanto, restará ao professor a responsabilidade de orientar as pesquisas e as propostas apresentadas até a resolução do caso apresentado.

Embasado nisto, o objetivo deste trabalho consistiu na elaboração e aplicação de um caso para abordar os rótulos nos produtos alimentícios, considerando que este assunto permeia o cotidiano dos alunos, podendo ser utilizado para contribuir no processo de ensino e aprendizagem de conceitos que envolvem a química tais como: caloria, \%VD (porcentagem de valores diários), a forma como está presente o elemento sódio e a confusão entre os termos diet, light, normal.

\section{Metodologia}

As atividades foram aplicadas em uma turma de 27 alunos do $2^{\circ}$ Ano do Ensino Médio de um escola pública estadual, situada na cidade de Londrina - Paraná, que adota o sistema de blocos, com aulas geminadas. O sistema de blocos consiste na divisão do ensino anual em dois blocos, no qual as disciplinas estudadas durante o ano letivo são organizadas por semestres.

A aplicação da proposta se deu no decorrer do $2^{\circ}$ bimestre de 2009 e teve duração de 6 horas-aula com a turma dividida em quatro grupos, conforme o quadro a seguir.

Quadro 1: Distribuição das atividades

\begin{tabular}{|c|c|}
\hline Aulas & Atividades \\
\hline $1^{\underline{a}}$ e $2^{\underline{a}}$ & $\begin{array}{l}\text { - Questionário de sondagem } \\
\text { - Leitura do caso } \\
\text { - Entrega e análise dos rótulos }\end{array}$ \\
\hline $3 \underline{a}$ e 4a & $\begin{array}{l}\text { - Entrega e leitura dos artigos } \\
\text { - Discussão em grupo e elaboração da apresentação }\end{array}$ \\
\hline 5 a e 6a & $\begin{array}{l}\text { - Apresentação do trabalho de cada equipe } \\
\text { - Questionário final e conclusão das atividades }\end{array}$ \\
\hline
\end{tabular}


Como o assunto sobre rótulos é muito extenso, para esse estudo buscou-se limitar aos conceitos sobre diet, light, normal, caloria, \%VD e a forma como se apresenta o elemento sódio, pois esses ainda causam confusão ou são de total desconhecimento para as pessoas que compram determinados produtos e os consomem.

Inicialmente foi aplicado um questionário de sondagem, Quadro 2, para detectar os conhecimentos prévios dos alunos sobre o assunto a ser abordado.

Quadro 2: Questionário de sondagem do conhecimento sobre rótulos nutricionais.

Questões

1) Você tem o hábito de observar e ler as informações contidas nas embalagens dos alimentos que consome?

2) O sódio indica que os alimentos possuem sabor salgado?

3) Você sabe o que é valor energético e a sua importância para alimentação?

4) Você sabe o que significa e acha importante conhecer este valor \%VD?

5) Você sabe a diferença entre produtos diet, light e normal?

Após, foi feita a leitura do caso, Quadro 3, em grupo sendo conduzido pelo professor em voz alta.

Quadro 3: Estudo de Caso aplicado aos estudantes na atividade desenvolvida.

Rótulos nutricionais: um quebra cabeça de informações!

A jovem Maria estava estudando para o vestibular de Química que faria no final do mês quando recebeu um telefonema no meio da tarde. Do outro lado da linha era a sua avó toda preocupada, pois tinha acabado de voltar de uma consulta médica:

- Oi Maria! Tudo bem com você?!

- Tudo bem vovó. Por que a senhora está com essa voz preocupada?

- É que eu fiz uma consulta com o meu médico e ele pediu para eu ter um cuidado especial com a comida que eu compro e prestar mais atenção nos rótulos dos alimentos.

- Olha vovó ele está certo. É sempre bom sabermos o que estamos comprando, assim podemos nos alimentar melhor e termos uma vida mais saudável.

- Então, é por isso que eu resolvi te ligar, pois eu sei que você gosta desse assunto e pode me ajudar. 
- Sim, é claro que eu ajudo!

- Bem essas coisas são muito complicadas e eu não entendo nada do que está escrito naqueles rótulos.

- Calma vovó. Estou indo na casa da senhora e vamos entender junto o que são todas essas informações!

Vocês, estudantes de química, poderiam também ajudar a Maria e a sua avó a entender as informações contidas nos rótulos dos alimentos, como: \%VD, valor energético, sódio, produtos diet, light e normal.

Após a leitura do caso foram entregues aos grupos, rótulos de gelatinas e sucos de produtos diet, light e normal, para que os alunos observassem as diferenças contidas nos rótulos desses produtos. As figuras 1, 2, 3, 4 e 5, são exemplos de rótulos de sucos líquidos e em pó:

\begin{tabular}{|c|c|c|}
\hline \multicolumn{3}{|c|}{$\begin{array}{l}\text { INFORMAÇÃO NUTRICIONAL } \\
\text { Porção } 6 \mathrm{~g} \text { (1/5 da embalagem) }\end{array}$} \\
\hline \multicolumn{2}{|c|}{ Quantidade por porção } & \multirow{2}{*}{$\frac{\% V D(*)}{1}$} \\
\hline Valor Energético & $26 \mathrm{kcal}=109 \mathrm{~kJ}$ & \\
\hline Carboidratos & $5,1 \mathrm{~g}$ & 2 \\
\hline Sódio & $24 m g$ & 1 \\
\hline Vitamina C & $6,7 \mathrm{mg}$ & 15 \\
\hline \multicolumn{3}{|c|}{$\begin{array}{l}\text { Nāo contém quantidade significativa de proténas, gorduras } \\
\text { totais, gorduras saturadas, gorduras trans e fibra alimentar. }\end{array}$} \\
\hline
\end{tabular}

Figura 1: Rótulo do suco em pó normal.

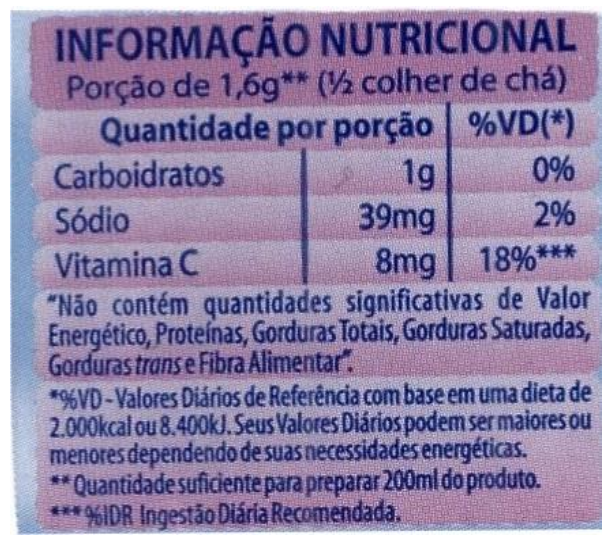

Figura 3: Rótulo do suco diet em pó

\begin{tabular}{|c|c|c|}
\hline \multicolumn{3}{|c|}{$\begin{array}{l}\text { INFORMAÇÃO NUTRICIONAL } \\
\text { Porção } 2 \mathrm{~g}(1 / 5 \text { da embalagem) }\end{array}$} \\
\hline \multicolumn{2}{|c|}{ Quantidade por porção } & $\left.\% \mathrm{VD}^{*}\right)$ \\
\hline Valor Energético & $7 \mathrm{kcal}=29 \mathrm{~kJ}$ & 0 \\
\hline Carboidratos, & $1,7 \mathrm{~g}$ & 1 \\
\hline dos quais: Açúcares & $\mathrm{Og}$ & ** \\
\hline Sódio & $21 \mathrm{mg}$ & 1 \\
\hline \multicolumn{3}{|c|}{$\begin{array}{l}\text { Náo contém quantidade significativa de proteinas, gorduras } \\
\text { totais, gorduras saturadas, gorduras trans e fibra alimentar. }\end{array}$} \\
\hline 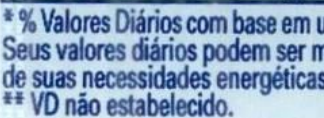 & & \\
\hline
\end{tabular}

Figura 2: Rótulo do suco em pó light - zero açúcar

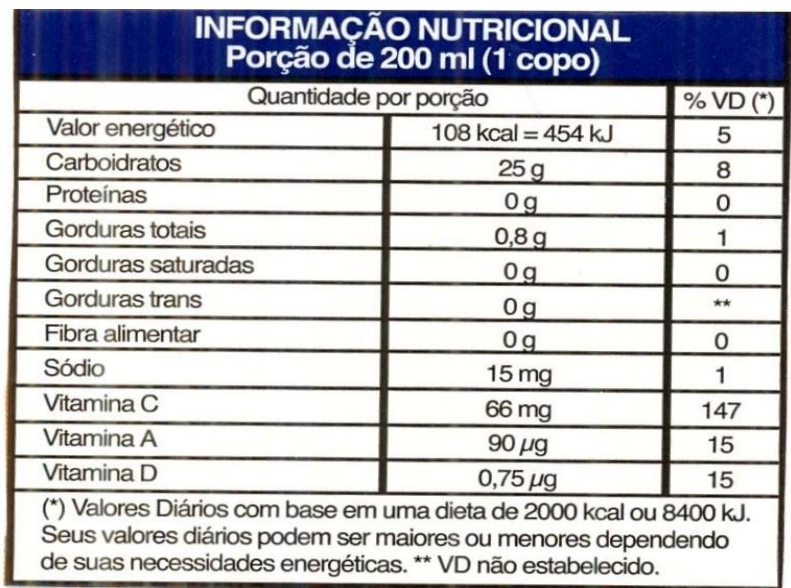

Figura 4: Rótulo do suco líquido normal. zero açúcar. 


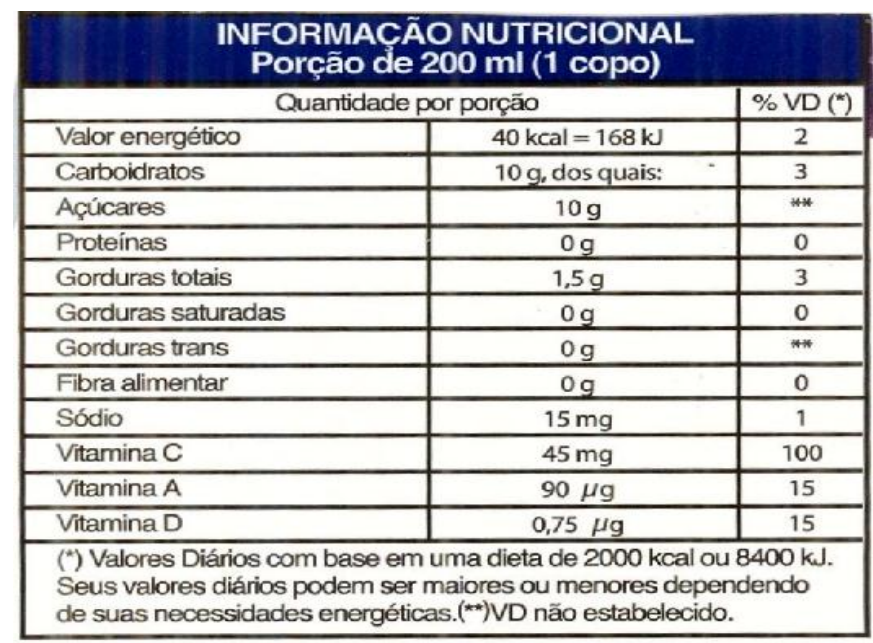

\section{A porção de $100 \mathrm{ml}$ de Néctar de Uva Light possui valor energético $68 \%$ menor se comparado ao produto convencional}

Figura 5: Rótulo do suco líquido light.

Após os apontamentos iniciais, com a necessidade de um maior aprofundamento e uma maior compreensão do tema exposto, foram entregues aos alunos três artigos para leitura. Esse subsídio foi mais uma ferramenta para ajudá-los na possível solução do caso apresentado.

Estes artigos encontram-se publicados na revista Química Nova na Escola e são: De olho nos rótulos: compreendendo a unidade caloria (Chassot et al., 2005); Diet ou Light: Qual a Diferença? (Silva e Furtado, 2005) e Interpretação de Rótulos de Alimentos no Ensino de Química (Neves et al., 2009).

Os alunos tomaram a iniciativa de pesquisar acerca dos assuntos discutidos em sala de aula para complementar a discussão e tentar resolver o caso na próxima aula, com as novas informações e materiais para montar uma apresentação final. Após o retorno, os alunos munidos dessas informações, se reuniram em seus grupos, debateram e decidiram como organizar e apresentar suas pesquisas no fechamento do trabalho.

Cada grupo fez sua apresentação de forma expositiva, com cartazes e com a ajuda de vídeos explicativos sobre os assuntos trabalhados, num período de no máximo 15 minutos por grupo, sendo que ao final de todas as apresentações houve ainda: debates sobre o assunto discutido, a escolha da solução com relação ao problema apresentado e, também, a aprendizagem proporcionada pelo estudo de caso.

Para o encerramento do estudo, foi aplicado um questionário final, com as mesmas questões dadas inicialmente, Quadro 2, para se obter informações e uma comparação da aprendizagem pelo método proposto. 


\section{Análise e discussão dos resultados}

$\mathrm{Na}$ aplicação do método do estudo de casos, observou-se inicialmente que alguns alunos mostraram-se resistentes, pois para eles a mudança de estratégias de ensino leva-os a temer que a dificuldade dessa forma de aprendizagem seja muita maior do que no processo de ensino e aprendizagem em que estão acostumados e inseridos dentro da sua vida escolar, ou seja, atuando como sujeitos passivos.

Com a aplicação do questionário de sondagem sobre o assunto que seria aplicado e com uma explanação sobre como o estudo seria construído nas aulas, a barreira inicial mostrada pelos alunos começou a não mais existir, sendo necessário que houvesse, portanto, uma visão ampla da forma de condução do trabalho para que o processo fosse aceito pelos alunos.

A utilização e a leitura de textos científicos numa linguagem acessível, os auxiliou a manter o interesse com o tema proposto e foi importante para criar uma empatia e manter o interesse na busca da solução para a situação-problema apresentada.

Com as discussões que se seguiam e o interesse crescente, a aplicação da metodologia teve um ganho perceptível em sua aceitação, quando partiu dos próprios alunos o interesse de fazer uma apresentação com a aplicação do conhecimento adquirido de forma expositiva e com o uso de alguns vídeos, como, Cuidados com a alimentação - sódio ${ }^{1}$, Diet e light. Você conhece a diferença??? ${ }^{2}$ e Calcular calorias manualmente ${ }^{3}$.

Com o resultado obtido no questionário aplicado no início e no final do trabalho, tem-se a representação de um bom nível de aprendizado alcançado com o método, como demonstrado nas Figuras 6, 7, 8, 9 e 10:

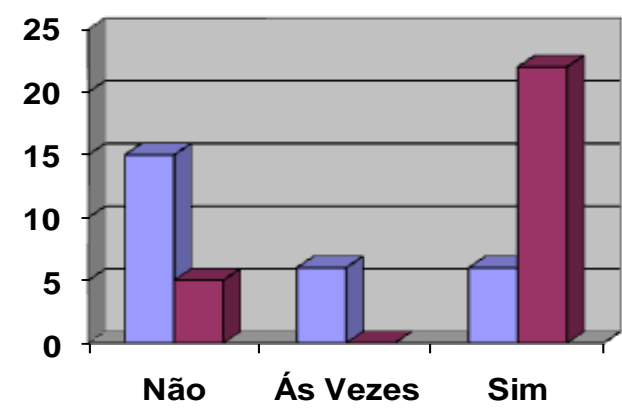

\begin{tabular}{|l}
$\square$ Resposta no início do \\
trabalho \\
$\square$ Resposta no final do \\
trabalho
\end{tabular}
trabalho

Figura 6: Você tem o hábito de observar e ler as informações contidas nas embalagens dos limentos que consome?

1 Disponível em: http://www.youtube.com/watch?v=M6OHgU0UBwM, acessada em novembro de 2009. de 2009.

${ }^{2}$ Disponível em: http://www.youtube.com/watch?v=jvb586M2p40, acessada em novembro novembro de 2009 . 
Conforme ilustra a Figura 6, poucos alunos tinham o hábito de observar e ler as informações contidas nas embalagens, mas com o estudo dirigido e ao final do trabalho do estudo de caso, houve uma mudança de atitude. Verificou-se que o interesse na observação das informações dos rótulos se tornou maior, inclusive sobre assuntos que não foram tratados diretamente no trabalho como: antioxidantes, estabilizantes, corantes, etc.

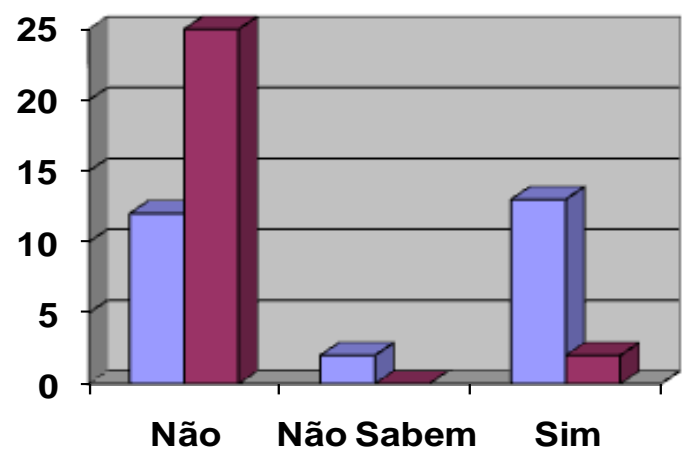

$\square$ Resposta no início do trabalho

- Resposta no final do trabalho

Figura 7: O sódio indica que os alimentos possuem sabor salgado?

$\mathrm{Na}$ Figura 7, mais da metade dos alunos na turma tinham como entendimento da palavra sódio a concepção do sabor salgado. Com a aplicação do estudo de caso e as discussões realizadas em sala de aula ao longo da realização do trabalho, houve por eles uma nova interpretação, na qual a quantidade de sódio não interfere diretamente com o sabor dos alimentos que são consumidos, mas sim a função de contribuir para regular a pressão osmótica do sangue, plasma e fluidos intracelulares, e assim, manter o equilíbrio hídrico do organismo e a transmissão dos impulsos nervosos. Mas, por outro lado, uma ingestão em excesso de sódio é um fator de risco que pode agravar quadros de hipertensão arterial.

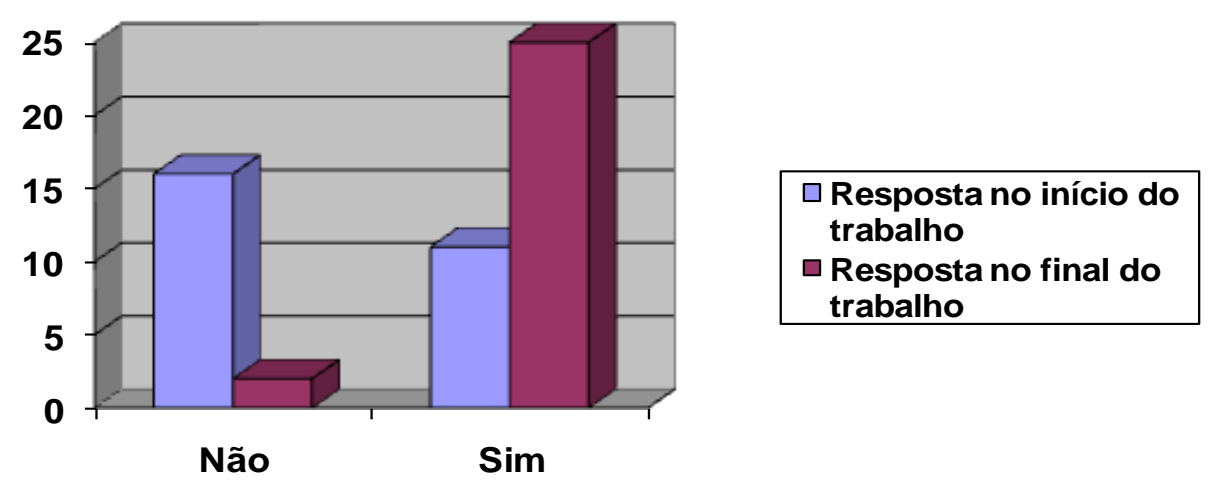

Figura 8: Você sabe o que é valor energético e a sua importância para alimentação? 
A análise da Figura 8 indica que, no início do trabalho, muitos alunos ainda não reconhecem o termo valor energético, mas após realizarem o trabalho, a partir das discussões em sala de aula, das leituras realizadas e dos vídeos apresentados, os alunos passaram a associar valor energético com a palavra caloria que eles já tinham algum conhecimento e dessa forma ficou mais fácil para eles perceberem a importância dessa informação para a alimentação.

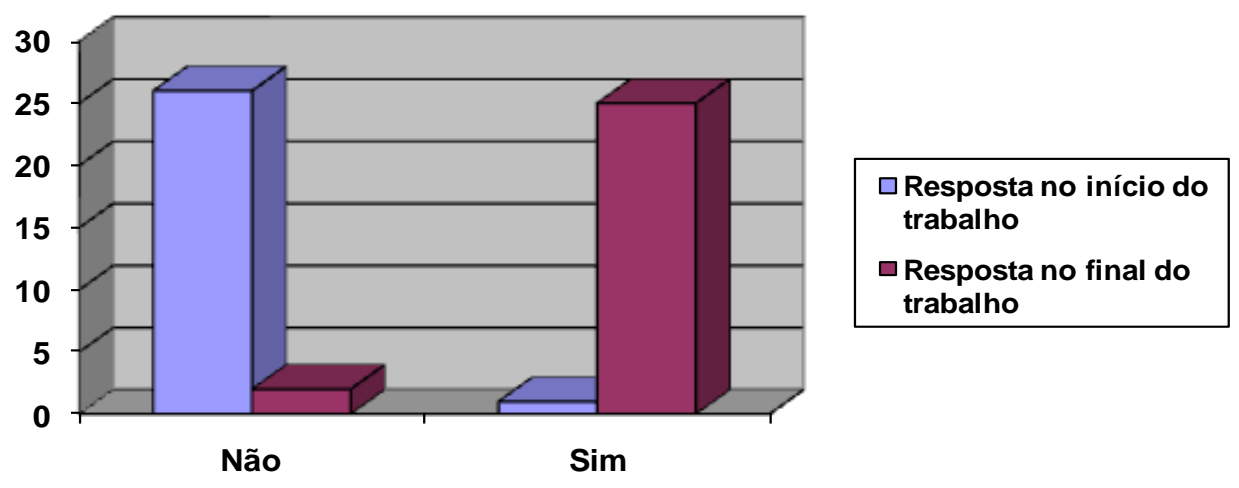

Figura 9: Você sabe o que significa e acha importante conhecer este valor \%VD?

Na Figura 9, verifica-se que quase a totalidade dos alunos, no início do trabalho, não sabia reconhecer o valor \%VD, após a leitura dos textos e aplicação do estudo de caso, essa interpretação do termo foi quase totalmente reconhecida e compreendida pelos alunos ao final do trabalho.

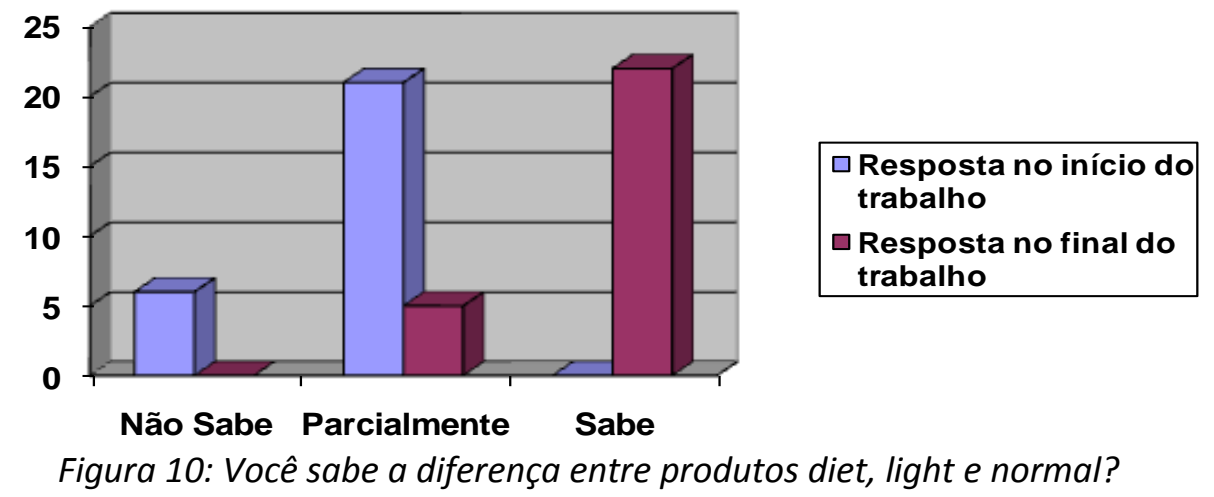

Conforme ilustra a Figura 10, muitos alunos, antes da realização da atividade, tinham um conhecimento parcial dos termos diet, light e normal. Este conhecimento parcial pode ser confirmado quando foi solicitado aos alunos que falassem a respeito da diferença entre esses termos, os alunos mostraram-se confusos. Com a aplicação do estudo de caso, os alunos 
puderam reconhecer a diferença entre eles e com isso o resultado obtido ao final do trabalho foi totalmente satisfatório. Esclarecendo, portanto, muitas dúvidas sobre o uso desses termos nos rótulos dos alimentos.

Em todas as apresentações orais os alunos simulavam a presença da vovó de Maria e explicavam criteriosamente o significado de cada informação contida nos rótulos. As explicações estavam embasadas nas leituras realizadas dos artigos propostos, em pesquisas realizadas fora da sala de aula e nos debates realizados em sala. Desse modo, longe de uma aula passiva, houve vários momentos de debates de uma forma cooperativa na construção do conhecimento.

Após todo o trabalho realizado, foi dado como caso resolvido, que a informação dos rótulos quando conhecida de maneira adequada é um importante aliado no controle de uma alimentação saudável e, que com um maior cuidado, também se pode evitar o agravamento de doenças por uma alimentação em que o devido conhecimento daquilo que se consome é de grande importância.

\section{Considerações Finais}

Após a aplicação do caso e a apresentação dos trabalhos realizados pelos alunos em grupo, houve uma maior compreensão por parte dos mesmos quanto à importância dos rótulos nutricionais e aos conceitos químicos envolvidos, dentro de cada segmento que foi abordado.

Ficou demonstrada, de acordo com o comparativo das respostas obtidas pelo questionário no início e no final do trabalho, pelas discussões realizadas durante as aulas e pela apresentação oral, que a metodologia de estudo de casos é uma ferramenta importante que pode ser desfrutada pelo professor em sala de aula, obtendo-se bons resultados numa concepção de ensino diferente do tradicional.

\section{Referências}

Brito, J. Q. A.; Sá, L. P. Estratégias promotoras da argumentação sobre questões sócio-científicas com alunos do ensino médio. Revista electrónica de enseñanza de las ciências, v. 9, n. 3, p. 505529, 2010.

Chassot, A.; Venquiaruto, I. D.; Dallago, R. M. De olho nos rótulos: compreendendo a unidade caloria. Química nova na escola, n. 21, p. 10-12, 2005.

Herreid, C. F. Sorting potatoes for miss bonner - bringing order to case-study methodology through a classification scheme. Journal of college science teaching, v. 27, n. 4, p. 236-239, 1998a.

Herreid, C. F. What makes a good case? Journal of college science teaching, v. 27, n. 3, p. 163$169,1998 b$. 
Neves A. P.; Guimarães P. I. C.; Merçon F. Interpretação de rótulos de alimentos no ensino de química. Química nova na escola, v. 31, n. 1, p. 34-39, 2009.

Pinheiro, A. N.; Medeiros, E. L.; Oliveira, A. C. Estudos de casos na formação de professores de química. Química nova na escola, v. 33, n. 9, p. 1996-2002, 2010.

Sá, L. P; Queiroz, S. L. Estudo de casos no ensino de química. Campinas, São Paulo: Átomo, 2009.

Silva, R. M. G.; Furtado,S. T. F. Diet ou light: qual a diferença? Química nova na escola, n. 21, p. 14-16, 2005.

Waterman, M. A. Investigative case study approach for biology learning. Bioscene: journal of college biology teaching, v. 24, n. 1, p. 3-10, 1998.

Fabiele Cristiane Dias Broietti - Licenciada em Química pela Universidade Estadual de Londrina (UEL), especialista em Ensino de Química pela UEL, mestre em Ensino de Ciências na Modalidade Química pela UEL e doutoranda em Ensino de Ciências Modalidade Química pela Universidade Estadual de Maringá (UEM), é professora do Departamento de Química da UEL. fabieledias@uel.br

Flaveli Aparecida de Souza Almeida - Licenciada em Química pela Universidade Estadual de Londrina (UEL), especialista em Química pela UEL, mestre em Química Analítica pela Pontifícia Universidade Católica do Rio de Janeiro (PUC/RJ) e doutora em Ciências pela PUC/RJ, é professora do Departamento de Química da UEL. - flaveli@uel.br

Renata Cristina Mello Alves Silva - Licenciada em Química pela Universidade Estadual de Londrina (UEL), especialista em Ensino de Química pela UEL, é professora do Ensino Médio pela Secretaria de Estado da Educação do Paraná (SEED/PR). - rencmas@hotmail.com 